\title{
Wall-to-Wall Forest Mapping Based on Digital Surface Models from Image-Based Point Clouds and a NFI Forest Definition
}

\author{
Lars T. Waser ${ }^{1, *}$, Christoph Fischer ${ }^{2, \dagger}$, Zuyuan Wang ${ }^{1,+}$ and Christian Ginzler ${ }^{1}$ \\ Received: 16 September 2015; Accepted: 4 December 2015; Published: 11 December 2015 \\ Academic Editor: Joanne C. White \\ 1 Department of Landuse Dynamics, Swiss Federal Institute for Forest, Snow and Landscape Research (WSL), \\ Zuercherstrasse 111, CH-8903 Birmensdorf, Switzerland; zuyuan.wang@wsl.ch (Z.W.); ginzler@wsl.ch (C.G.) \\ 2 Scientific Service Swiss NFI, Swiss Federal Institute for Forest, Snow and Landscape Research (WSL), \\ CH-8903 Birmensdorf, Switzerland; christoph.fischer@wsl.ch \\ * Correspondence: waser@wsl.ch; Tel.: +41-44-739-2292 \\ + These authors contributed equally to this work.
}

\begin{abstract}
Forest mapping is an important source of information for assessing woodland resources and a key issue for any National Forest Inventory (NFI). In the present study, a detailed wall-to-wall forest cover map was generated for all of Switzerland, which meets the requirement of the Swiss NFI forest definition. The workflow is highly automated and based on digital surface models from image-based point clouds of airborne digital sensor data. It fully takes into account the four key criteria of minimum tree height, crown coverage, width, and land use. The forest cover map was validated using almost 10,000 terrestrial and stereo-interpreted NFI plots, which verified $97 \%$ agreement overall. This validation implies different categories such as five production regions, altitude, tree type, and distance to the forest border. Overall accuracy was lower at forest borders but increased with increasing distance from the forest border. Commission errors remained stable at around $10 \%$, but increased to $17.6 \%$ at the upper tree line. Omission errors were low at $1 \%-10 \%$, but also increased with altitude and mainly occurred at the upper tree line (19.7\%). The main reasons for this are the lower image quality and the NFI height definition for forest which apparently excludes shrub forest from the mask. The presented forest mapping approach is superior to existing products due to its national coverage, high level of detail, regular updating, and implementation of the land use criteria.
\end{abstract}

Keywords: land use; canopy height model; airborne digital sensor; NFI plots; stratification

\section{Introduction}

Wall-to-wall forest mapping is a critical task, because the resulting datasets such as forest cover maps are a fundamental input for a broad range of applications from global environmental change assessment to local forest management planning. Forest maps are essential for governmental authorities, international reporting -including the Kyoto protocol, in the framework of Reducing Emissions from Deforestation and Degradation (REDD), forest disturbance assessments, biodiversity and restoration programs, and our understanding of the distribution of forest patches, which are relevant for connectivity studies [1,2]. However, to our knowledge, there are currently no operational attempts to produce wall-to-wall forest cover maps in the framework of a National Forest Inventory (NFI) - at least in Europe. In fact, these mostly design-based sample inventories serve as the basis for forest resources assessment and thus estimate a variety of forest attributes (e.g., size of forested area, growing stock, tree species etc. [3]). Existing mapping sources—such as stand maps—are rather 
used to quantify forest area and forest attributes in several NFIs (Czech Republic, Great Britain, Korea, The Netherlands, Romania, Slovenia, and Spain) [4].

According to Koch et al. [5], remote sensing based forest mapping has a long tradition and covers a variety of techniques and data, including the whole spectrum of active and passive sensors. Traditionally, forest cover maps have been the product of visual interpretations and delineation of aerial imagery in combination with field visits. Thus, their development is time consuming, and restricted to relatively small areas. In addition, shadow effects limit the exact detection of forest borders or small gaps.

In recent years, optical remote sensing data, and in particular digital aerial images, have been incorporated into operational NFIs and the required estimates obtained from remote sensing-based maps can now be expressed in forms similar to sample-based estimates [6]. The NFI of most countries (including Switzerland) rely on remote sensing data mainly to stratify sample plots to distinguish forest plots (to be visited in field) and non-forest plots. Additional benefits of remotely sensed data are the assessment of tree resources outside forest or outside sample plots within the forest for diverse and detailed forest statistics, stratification and reduced estimation errors [7-9], providing relevant spatially explicit products, and optimized planning and reduction of field visits $[4,10]$. At the same time, the required information for forest mapping can be provided precisely by combining NFI data with remote sensing data and techniques $[9,11]$. This can be done, for example by extrapolating estimates from field plot samples using the k-nearest neighbor (k-NN) algorithm [12].

In the last decade, partly automated forest mapping approaches based on remote sensing techniques and data have often been performed, on scales ranging from global to forest company level, and been carried out in the framework of global mapping or resources assessment programs. Mentionable are the Global Forest Resources Assessment (FRA 2010) Remote Sensing Survey [13] initiated by the Food and Agriculture Organization (FAO), the Global Forest Watch (GFW) [14] initiative by the World Resources Institute, the Global Land Cover mapping approach (GLC) [15], the global forest/non-forest mapping initiated by the Japan Aerospace Exploration Agency (JAXA) [16], and the European 2006 Forest cover map [17] from the Joint Research Center (JRC). Other forest mapping approaches that are mostly restricted to relatively small areas have been performed in the framework of change detection studies in general [18,19], FAO forest definition applications [20], the assessment of clear-cuts [21] or deforestation such as REDD [22]. Recently, Hansen et al. [2] generated a spatially and temporally detailed global forest and forest change map, which provides valuable information for many land use related applications at regional level. Schepaschenko et al. [23] present a global hybrid forest map approach based on remote sensing data, maps and FAO statistics. Shimada et al. [24] provides new global forest/non-forest maps based on ALOS PALSAR data (2007-2010).

Besides the undoubted value for many applications and users, when compared with NFI sample plot estimations, current forest cover maps clearly suffer from inconsistencies with respect to clear forest definitions and, consequently, technically correct forest mapping. The main inconsistencies are summarized below:

(i) Existing forest cover maps have often been produced with an oversimplified definition of forest, and are therefore not congruent with the respective NFI definition, which consists mostly of the key criteria: (1) minimum tree height; (2) minimum tree crown coverage; (3) minimum area and/or minimum width; and (4) land use [4].

(ii) Problems arise regarding land use, which is a key parameter in NFI forest definition but hardly assessable when using remotely sensed data-in contrast to land cover which is assessable. For example, a temporary unstocked area, e.g., after impacts such as fire, storm, or harvesting will be identified as non-forest area when using remote sensing data and techniques, but will in fact maintain its status as a forest within the NFI.

(iii) Unavoidable restrictions occur due to the simplified level of detail of existing forest cover maps, which results in an insufficient and inaccurate representation of forest borders, gaps, and parts with open or dense forests. 
In recent years, highly automated methods for the extraction of forest area based on Airborne Laser Scanning (ALS) data have been proposed [25-27]. ALS has particularly revolutionized forest inventories with its great potential to acquire three-dimensional (3D) forest vertical structure data to extract a variety of forest attributes [28]. An excellent overview is given in [8]. Greater precision in forest mapping is now possible with the acquisition of 3D point data by matching aerial stereo-images [18,29-31] or satellite images [32], coupled with advances in image processing algorithms. Moreover, the high costs of ALS data acquisition and processing, the limited technical capacity of many forest management agencies, and the traditional role that imagery has played in forest inventories, explain the growing interest in alternative technologies for the extraction of 3D information in the forestry sector. Nevertheless, forest cover maps at greater than the provincial scale are still rare in central European countries. For example, although the Swiss NFI had great interest in acquiring additional area-wide data, until recently, forest mapping approaches have only existed at the cantonal level (mostly based on manual delineation of aerial images).

New perspectives for wall-to-wall forest mapping are emerging through digital aerial stereo-images, which are likely —in contrast to ALS — updated more regularly by national or regional mapping agencies in several countries [6]. The possibility of extending the spatially and temporarily limited NFI plot information to a continuous landscape-level representation-such as wall-to-wall forest cover maps-has now become more feasible.

Switzerland is one of these countries, where the Federal Office of Topography (swisstopo) has been updating countrywide digital stereo-imagery every six years since 2005. The topographic landscape model (TLM) provides the land use criteria that are necessary for the definition of forest [33]. It is superior to the currently available CORINE 2006 land cover (CLC2006) with respect to the level of detail and updating and is the best available proxy to the "forestry" land use. With these two datasets, wall-to-wall mapping requirements, as well as those regarding the NFI and technical knowhow, are now entirely met.

The main objective of the present study is to generate a detailed wall-to-wall forest cover map for Switzerland that takes the Swiss NFI forest definition into account. The focus is on implementing the key criteria (1) minimum tree height; (2) minimum tree crown coverage; (3) minimum width; and (4) land use. Its suitability for NFI purposes is entirely supported by the application of the land use criteria and its high level of detail, especially regarding forest borders and gaps. The proposed method is highly automated and is based on image-based point clouds from ADS80 digital stereo-imagery. The entire workflow consists of several single processing steps, thus enabling easy adaptation to any other forest definition. It demonstrates that it is now feasible to produce wall-to-wall forest cover maps in a timely and cost-effective manner. In this paper, we (i) demonstrate a straight forward method to use height information from image-based point clouds to derive a countrywide forest cover map; (ii) the implementation of the Swiss NFI forest definition including the land use criterion; and (iii) validate the results using almost 10,000 NFI plots.

Results are validated with respect to different aspects such as altitude, production area, forest type, age, and distance to the forest border. The main benefits for the Swiss NFI are manifold. The forest cover map could be used as a cost-effective substitute for aerial image interpretation. Thus, it also enables further planning, implementation, and optimization of expensive field surveys of forest inventories. Additionally, it can be used as support when assessing the accessibility of any forest area, which is important when dealing with harvesting issues.

\section{Material}

\subsection{Study Area}

The country of Switzerland is located between $5^{\circ} 57^{\prime}$ and $10^{\circ} 29^{\prime} \mathrm{E}$ and $45^{\circ} 49^{\prime}$ and $47^{\circ} 48^{\prime} \mathrm{N}$. It covers $41,285 \mathrm{~km}^{2}$, with an altitudinal range between 197 and $4634 \mathrm{~m}$ a.s.l. Switzerland is characterized by different types of landscapes and is divided into five main forest production regions: 
the Jura in the northwest, the Central Plateau, the Prealps between the Central Plateau and the Alps, and the Southern Alps (Figure 1).

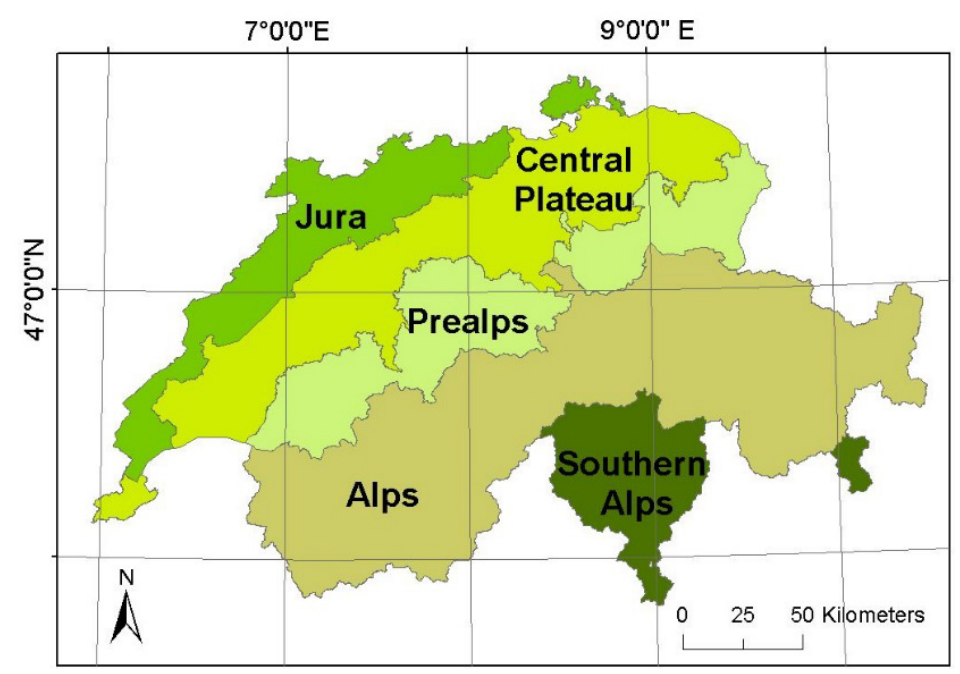

Figure 1. Swiss National Forest Inventory (NFI) forest production regions.

Switzerland has a varying regional proportion of forest cover with an average coverage of approx. $30 \%$ [34]. In the Central Plateau, the main settlement and agricultural zone, only $25 \%$ is covered by forest. This rises to $41 \%$ in the Jura and to $48 \%$ in the Southern Alps-a particularly forested mountainous region. Swiss forests consist of $43 \%$ pure coniferous, $19 \%$ mixed coniferous, $13 \%$ mixed deciduous, and $25 \%$ pure deciduous trees. Species richness is higher in the Central Plateau than in the mountainous regions. The most dominant tree species below $1200 \mathrm{~m}$ a.s.l. are beech (Fagus sylvatica), ash (Fraxinus excelsior), oak (Quercus sp.), white fir (Abies alba), and spruce (Picea abies). In higher regions, forests have an important protection function. The most dominant tree species are Scots pine (Pinus sylvestris), larch (Larix decidua), and spruce (Picea abies) in addition to a few deciduous tree species and softwood species along running waters. The upper tree line varies between $1600 \mathrm{~m}$ a.s.l. in the northern Prealps to approximately $2400 \mathrm{~m}$ a.s.l. in the valleys of the Central Alps, and is often dominated by Larix decidua, Pinus sp., and shrub forests with Pinus mugo and Alnus viridis. More detailed information on forests is provided in the third NFI report [35].

\subsection{Remote Sensing Data}

\subsubsection{Aerial Images}

Swisstopo has been acquiring stereo-image data using the Airborne Digital Sensors ADS40-SH40, SH52, and ADS80-SH82 for the entire country in a 3-year cycle since 2005. The images are acquired strip-wise East-West by Charge-Coupled Device (CCD) line-scanners, at four band true color and near-infrared (RGBI), with a 12-bit radiometric resolution, and ground sample distances (GSD) of $25-50 \mathrm{~cm}$. The main sensor specifications are summarized in Table 1 and can also be found in [36] or [37].

The tight flight program follows two modes enabling image acquisition in the leaf-on and leaf-off season for Swiss orthophoto production and the updating of the Topographic Landscape Model (TLM). Thus, $1 / 6$ of Switzerland is covered annually by each mode. In the present study, only the leaf-on stereo-image data from 2007 to 2012 are used. In total, 1710 stereo-image strips with a total length of $62,000 \mathrm{~km}$ cover the entire area of Switzerland. 
Table 1. Technical specifications of the ADS sensors.

\begin{tabular}{cccc}
\hline Parameter & ADS40-SH40 & ADS40-SH52 & ADS80-SH82 \\
\hline Time of operation & until 2007 & 2008-present & 2009-present \\
\hline Sensor & Three-line CCD scanner & Three-line CCD scanner & Three-line CCD scanner \\
\hline Dynamic range of the CCD & 12-bit & 12-bit & 12-bit \\
\hline & Panchromatic 465-680 & Panchromatic 465-680 & Panchromatic 465-680 \\
Spectral bands $(\mathrm{nm})$ & Blue 430-490 & Blue 428-492 & Blue 428-492 \\
& Green 535-585 & Green 533-587 & Green 533-587 \\
& Red 610-660 & Red 608-662 & Red 608-662 \\
& Near infrared 835-885 & Near infrared 833-887 & Near infrared 833-887 \\
\hline CCD elements & 8 CCD lines with & 12 CCD lines with & 12 CCD lines with \\
& 12,000 pixels each & 12,000 pixels each & 12,000 pixels each \\
\hline Pixel size $(\mu \mathrm{m})$ & 6.5 & 6.5 & 6.5 \\
\hline Bands used for matching & PAN/RGB & CIR/CIR & CIR/CIR \\
\hline
\end{tabular}

\subsubsection{Digital Surface Model}

Image-based point clouds from stereo-image strips of the ADS sensors were used to calculate a Digital Surface Model (DSM) for the entire country with a spatial resolution of $1 \times 1 \mathrm{~m}$. This highly automated workflow is described in detail in [37]. To optimize the calculation, Switzerland was divided into 165,500 image blocks, each of which measuring $0.5 \times 0.5 \mathrm{~km}$. For each block, image-matching was done independently with an overlapping buffer of $200 \mathrm{~m}$. A high level of completeness (97.4\%) of the matched points was obtained by using different correlation strategies, which were optimized for different image features (e.g., urban, flat, hilly, and steep areas). According to Ginzler and Hobi [37], the vertical agreement of the DSM based on stereo measurements on the same image pairs showed a Median Difference (MD) and Normalized Median Absolute Deviation (NMAD) of $-0.08 \mathrm{~m}$ and $1.76 \mathrm{~m}$ on coniferous trees and $0.16 \mathrm{~m}$ and $2.95 \mathrm{~m}$ on deciduous trees, respectively. On herb and grass vegetation, values of $-0.13 \mathrm{~m}$ and $0.49 \mathrm{~m}$ were found. The agreement of the Vegetation Height Model (VHM) with terrestrially measured trees for deciduous trees $(n=872)$ showed a median difference of $-0.56 \mathrm{~m}$ and a NMAD of $3.34 \mathrm{~m}$, and for coniferous trees $(n=1562)$ a median of $-1.86 \mathrm{~m}$ and a NMAD of $2.65 \mathrm{~m}$.

\subsubsection{Vegetation Height Model}

Prior to generating the VHM, a normalized Digital Surface Model (nDSM) was calculated by subtracting the Digital Terrain Model (DTM) from the DSM. This DTM "swissALTI ${ }^{3 D}$ " is the product of the national Light Detection and Ranging (LIDAR) campaign, and was provided by Swiss Federal Office of Topography [33]. The required VHM was generated by removing all buildings from the nDSM. For this, the building mask from the Topographic Landscape Model (TLM) from swisstopo was used. More details on the workflow of the countrywide image-matching can be found in Ginzler and Hobi [37].

\subsection{Reference Data}

The Swiss NFI is a sample-based survey that has been conducted every 10 years since 1983. Since 1993 it has applied a two-phase sampling approach incorporating aerial stereo-image interpretation and terrestrial survey. Since 2009 the NFI (4th survey) has been based on a continuous survey with plots surveyed over a period of nine years as opposed to a periodic survey. Thus, in the first phase, stereo-image interpretation is conducted yearly for an area of $50 \times 50 \mathrm{~m}$ around the plot center for one-ninth of the NFI sample plots on a $1.4 \times 1.4 \mathrm{~km}$ grid covering the entire area of Switzerland. In sum, 20,638 NFI samples are interpreted as "forest" or "non-forest", of which all "non-forest" plots are excluded from the terrestrial NFI surveys. In the second phase (the terrestrial survey), all plots that are classified as "forest", and the remaining "non-forest" plots which are closer than $5 \mathrm{~m}$ to an existing forest border, are visited. The NFI field teams follow a strict protocol [38] to make the final decision to 
classify these plots as either "forest" or "non-forest" (each visited plot consists of two concentric circles with a radius of $8 \mathrm{~m}$ and $12.6 \mathrm{~m}$, respectively).

To validate the forest cover map, a total of 9984 plots classified as "forest" (2437) and "non-forest" (7547) were used as the reference dataset. These plots were derived from both the manual stereo-image interpretation and the terrestrial survey of the fourth NFI (NFI4). During the terrestrial survey, the coordinates of all plot centres were measured using Trimble Geoexplorer. The horizontal accuracy after post-processing is $0.61 \pm 0.51 \mathrm{~m}$. Only plots for which the terrestrial survey was done after image acquisition were used. Validation includes several categories, i.e., distinction of the distance to the closest forest border of the forest cover map, the altitude a.s.l., the forest type (coniferous, deciduous), and the production regions of the NFI. All validation calculations were performed using the statistical software R [39].

\section{Method}

\subsection{Forest Definition of the Swiss National Forest Inventory}

A precise and unambiguous definition of forest is indispensable when mapping and comparing forest areas obtained by different inventories from the same or from different countries, regardless of whether they are based on terrestrial, remotely sensed, or combined approaches. According to Lund [40], more than 900 forest definitions are used throughout the world. Therefore, there is no universally accepted definition of the term forest. Most forest definitions incorporate the key criteria of (1) minimum tree height; (2) minimum crown coverage; and (3) minimum area and/or minimum width [4]. Figure 2 illustrates the three main criteria of the forest definition according to the Swiss NFI, assuming that the land use is forest. The minimum tree height must be higher than or equal to $3 \mathrm{~m}$, and is based on the mean height of the 25 thickest trees at breast height (DBH) in an area of $50 \times 50 \mathrm{~m}$ around the plot center (corresponding to the stereo-image interpretation area). For this, the reference area to estimate crown coverage is the same. All trees—regardless of their height—count for the calculation of crown coverage.

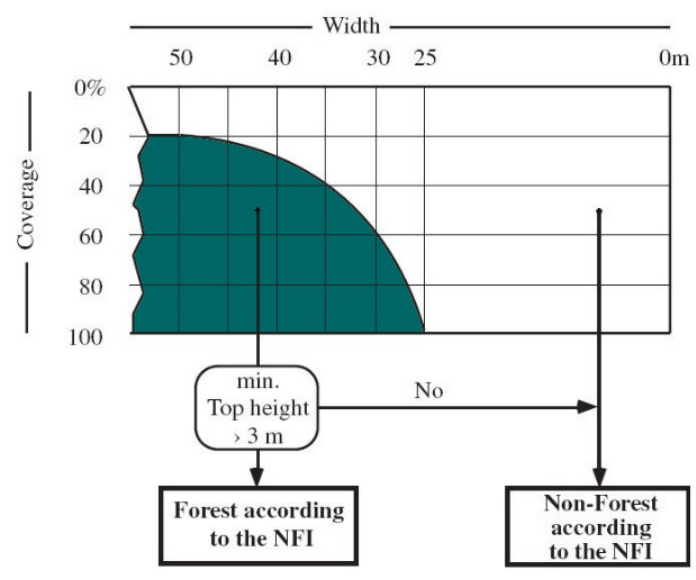

Figure 2. Forest definition based on minimum tree top height, crown coverage, and minimum width as applied in the Swiss NFI.

If a forest border crosses the interpretation area minimum width is also measured. This includes all trees that belong to the boundary and have a top that is higher than or equal to $3 \mathrm{~m}$, and a distance from each other of less than or equal to $25 \mathrm{~m}$ [41]. For example, a positive forest decision can be made if the minimum width of the stocked area is $25 \mathrm{~m}$ with a crown coverage of $100 \%$, or $50 \mathrm{~m}$ if the crown coverage is only $20 \%$. In the Swiss NFI, temporarily unstocked areas such as wind throws, or harvested areas maintain their status as forest. The fourth parameter of land use is not illustrated in 
Figure 2. More detailed information on the Swiss NFI forest definition and its application can be found in $[19,41,42]$.

Regarding the interpretation of aerial stereo-images, the implementation of the NFI forest definition is slightly different from that of the terrestrial survey. Each interpretation area of $50 \times 50 \mathrm{~m}$ consists of 25 equally spaced $(10 \mathrm{~m})$ lattice points arranged in a $5 \times 5$ point design [43]. On each lattice point, the elevation (m a.s.l.) is photogrammetrically measured and 11 land cover classes are interpreted. The effective height above ground at each lattice point is given by subtracting the DTM from the measured $3 \mathrm{D}$ lattice points. The crown coverage on the interpretation area is calculated using all points with land cover class "tree" and a height of higher than or equal to $3 \mathrm{~m}$. If there is a forest border on the plot, the border is digitized and the width is calculated [44].

\subsection{Workflow of Wall-To-Wall Forest Mapping}

A highly automated workflow based on ArcGIS functions implemented in Python scripts was developed in this study to generate a wall-to-wall forest cover map. Figure 3 shows the main steps and input datasets. The key criteria of the NFI forest definition are explained separately and more in detail in Sections 3.3 and 3.4.

(A)

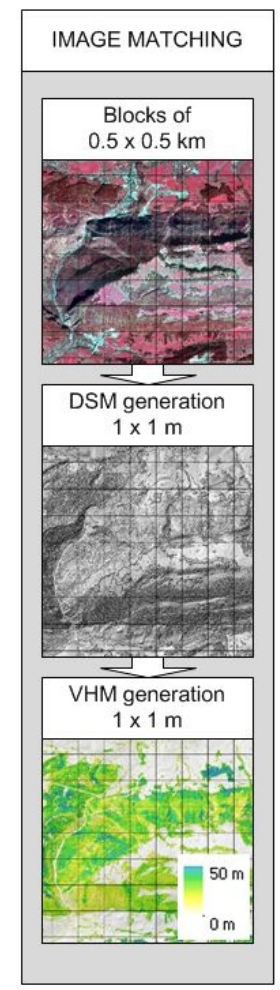

(B)

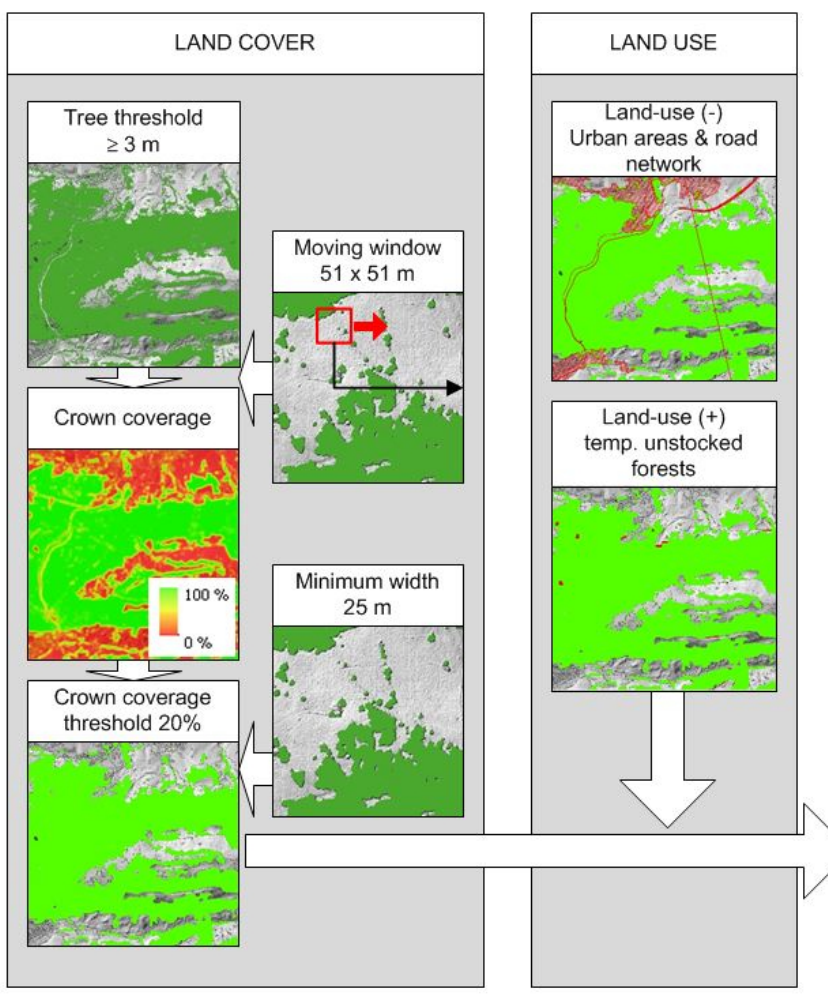

(D)

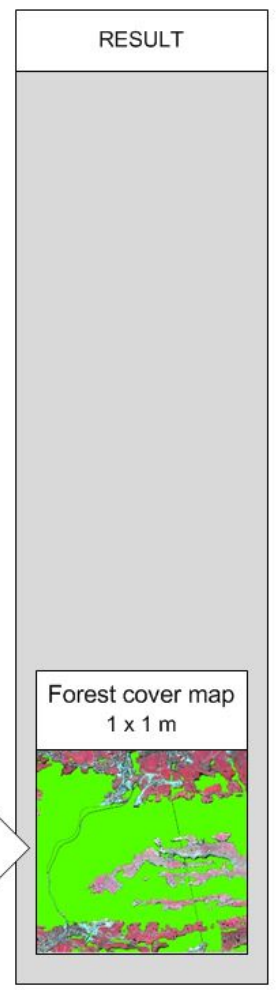

Figure 3. Workflow of the forest cover map implementing the existing Swiss NFI forest definition: (A) image matching; (B) preliminary forest cover map based on the land cover and the thresholds and parameter of the NFI forest definition (minimum tree height, crown coverage, and width); (C) removal of forest on other land and adding temporarily unstocked forests; and (D) final forest cover map.

Figure 3A shows the VHM based on image-based point clouds with a spatial resolution of $1 \mathrm{~m}$-which was derived from aerial image blocks of $0.5 \times 0.5 \mathrm{~km}$ [33]. Figure 3B shows a preliminary forest cover map based on the criteria of the NFI forest definition (minimum tree height, crown coverage, and minimum width). Figure $3 \mathrm{C}$ shows the application of the land use criteria in order to remove forest on other land (e.g., orchards, urban parks) while adding temporarily unstocked forests 
(e.g., wind throw, harvesting). Finally, in Figure 3D, the calculated forest cover map that implements all criteria of the forest definition as used in the stereo-image interpretation of the Swiss NFI is shown.

\subsection{Land Cover Criteria of the Swiss NFI}

Tree height and crown coverage are two essential criteria in forest definitions [4]. In the Swiss NFI, the minimum crown coverage threshold is $20 \%$ for forest. For the calculation of crown coverage, a defined reference area is essential [45]. In the Swiss NFI, it is an interpretation area of $50 \times 50 \mathrm{~m}$ around the sample plot center, which is used to estimate the percentage of crown coverage in the field. If the minimum threshold of $20 \%$ for crown coverage is fulfilled, the mean height of the 100 thickest trees $($ at $\mathrm{DBH})$ per hectare (25 thickest trees per $50 \times 50 \mathrm{~m}$ interpretation area) must be greater than or equal to $3 \mathrm{~m}$.

Figure 3B illustrates the reclassification of the VHM to vegetation with the NFI tree threshold. Crown coverage is calculated using a moving window approach, with a rectangle of $51 \times 51 \mathrm{~m}$ (odd number in order to obtain the center pixel) which corresponds almost to the interpretation area used in the terrestrial survey and in the stereo-image interpretation. For each center pixel, the proportion of vegetation greater than or equal to $3 \mathrm{~m}$ in height inside the window is calculated and the defined minimum crown coverage of $20 \%$ is applied. With this technique, forested area is particularly overestimated at the forest border (see Figure 4).
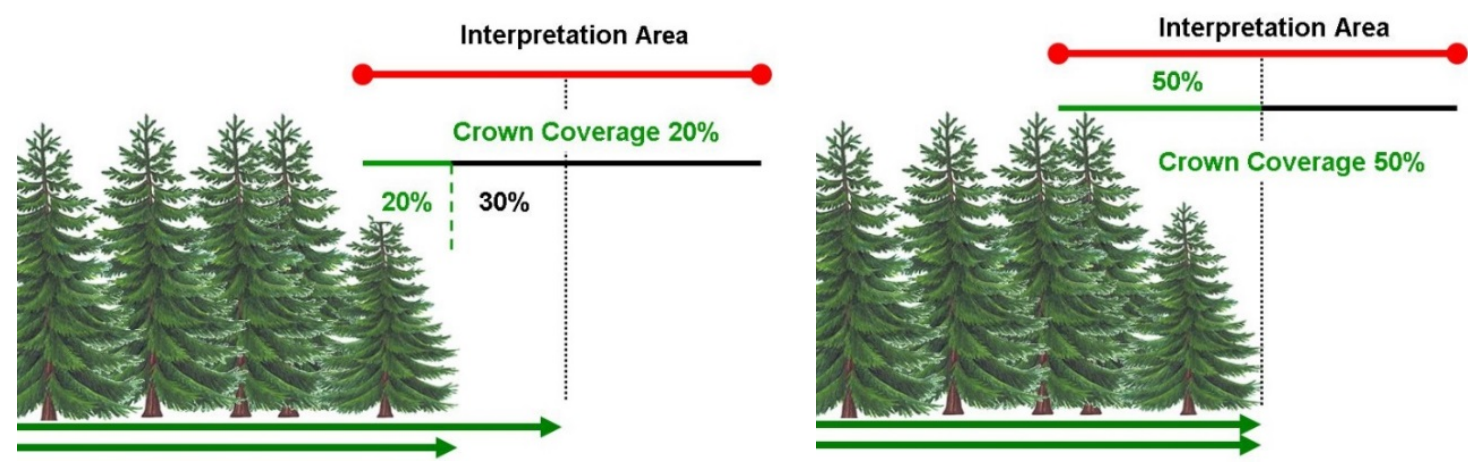

Figure 4. Problems related to the forest area at forest border within the interpretation area (red line) when its center (dashed line) is clearly outside the forest (left) and exactly at the forest border (right).

Figure 4 (left) illustrates that crown coverage is still $20 \%$ at the position of the dashed line, even though the center of the interpretation area is clearly outside the desired forested area as defined by the NFI. After the first forest cover map was generated using the $20 \%$ crown coverage threshold, the map was shrunk using morphological functions. The number of pixels for the shrink process at a specific position $i(X Y$-coordinates of this pixel) is a function of the size of the interpretation area and the minimum threshold of the crown coverage as described in Equation (1).

Number of pixels to shrink ${ }_{i}=$ window size $\times(0.5-$ threshold of crown coverage $) \times$ crown coverage $e_{i}$

Applying the Swiss NFI forest definition, this value is $51 \mathrm{~m}$ (window size) $\times(0.5-0.2)$ (threshold crown coverage $) \times 1(100 \%$ crown coverage at this location inside the forest) $=15.3$ pixels (rounded to 15). For the sake of simplification, the crown coverage inside the forest border at any location is set to 100\% (Equation (2)).

$$
\text { Number of pixels to shrink } \mathrm{k}_{i}=\text { window size } \times(0.5-\text { threshold of crown coverage })
$$

Figure 4 (right) illustrates the example for a 50\% crown coverage threshold within the interpretation area. In this case no shrinking would be applied.

Minimum area and width are other two essential parameters of a forest definition. However, both criteria are handled differently by many NFIs. Minimum width is more frequently used to 
separate areas of narrow tree elements-which do not fulfill the minimum requirements of the forest definition - from clearly defined forest areas [4].

In the present study, narrow tree elements (Figure 5A) below the minimum width of $25 \mathrm{~m}$ were removed using morphological functions while preserving the shape and size of larger objects. Forested areas were first shrunk by half of the minimum width of the forest definition (Figure 5B) and then expanded by half of the minimum width (Figure 5C). Elements smaller than the minimum width criterion were assigned the value zero (non-forest) and thus remain non-forest after the expansion of the shrunk forest areas.

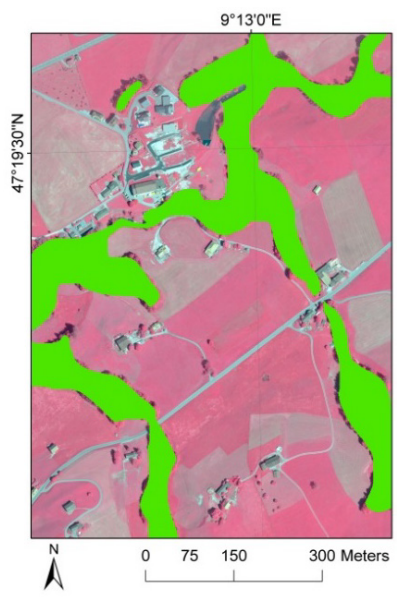

(A)

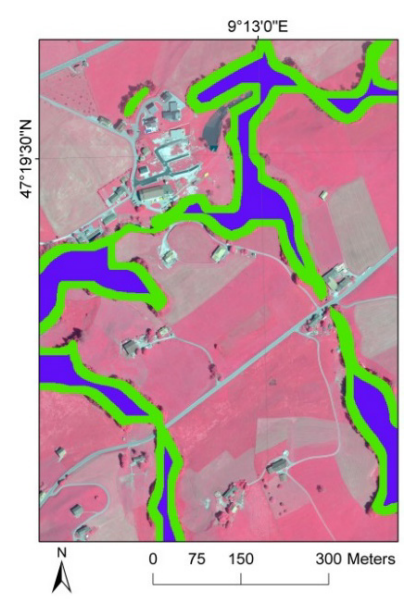

(B)

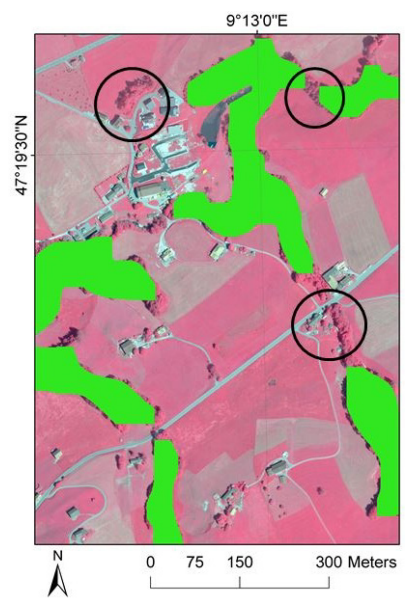

(C)

Figure 5. Removal of narrow elements from the forest cover map using morphological filters. (A) Forest cover map after applying the crown coverage threshold of 20\%; (B) Shrunk mask with half of the minimum width threshold; and (C) Removed narrow elements (circles) in the expanded forest cover map with half of the minimum width threshold.

\subsection{Land Use Criterion}

In the present study, temporarily unstocked areas with trees smaller than $3 \mathrm{~m}$ are extracted as non-forest in the VHM even though these areas are identified as forest according to the Swiss NFI definition because of their unchanged land use (Figure 6).
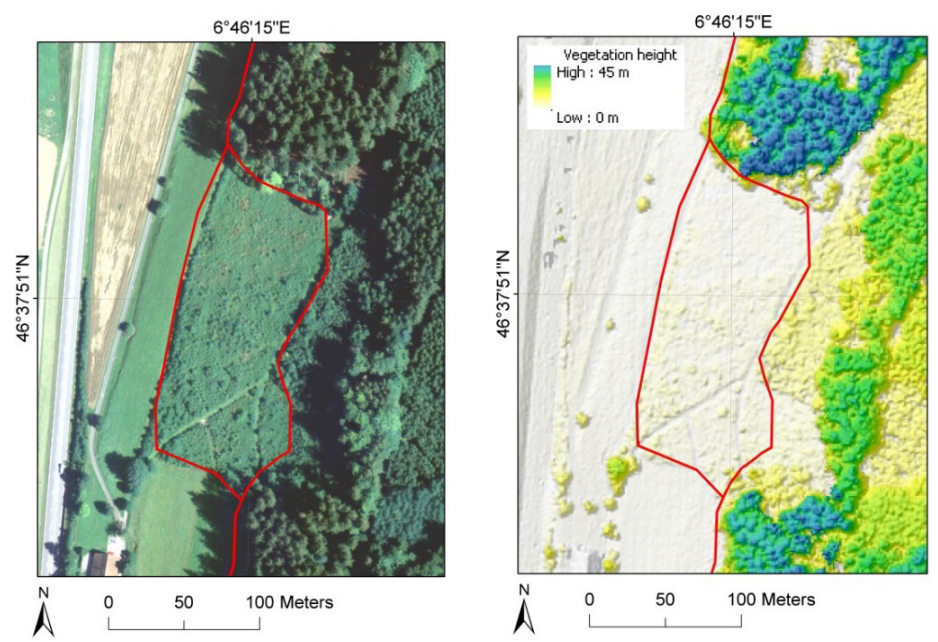

Figure 6. Example of a temporarily unstocked forest area, which remains identified as forest according to the Swiss NFI forest definition. (Left) Orthophoto with the temporarily unstocked forest in the center (red polygon); (Right) Corresponding vegetation height model with no trees in this area. 
Since the land use criterion could not be obtained from the VHM or from the aerial images, it was implemented using the respective cover from the Topographic Landscape Model (TLM) [33]. The TLM includes natural and artificial landscape objects, with the latter having a higher priority. Both types of objects are mostly manually stereo-interpreted following an updating cycle of six years for the entire country. Two classes from the TLM were integrated into the present forest mapping approach: the land cover class "closed forest" — which is actually a land use class-to compensate for temporarily unstocked forests, and the land use class "orchards" and "settlement" to eliminate forest area on other land use. Furthermore, since the exact definition of forest in the TLM is not published, all added polygons larger than 10 ha had to be checked visually $(n=2433)$. Finally, a last visual check was performed after filtering the forest cover map with this auxiliary TLM information.

\section{Results}

The final product is a wall-to-wall forest cover map for all of Switzerland covering a total forest area of $12,937.71 \mathrm{~km}^{2}$ — with a spatial resolution of $1 \mathrm{~m}$ (Figure 7). Its overall presentation appears to be reasonable-especially where forests in valleys and the high percentage of forest in the Southern Alps are clearly visible. The accuracy assessment of the forest cover map consists of both a comparison with NFI estimations (Section 4.1) and validation based on the NFI sample plot data (Section 4.2).

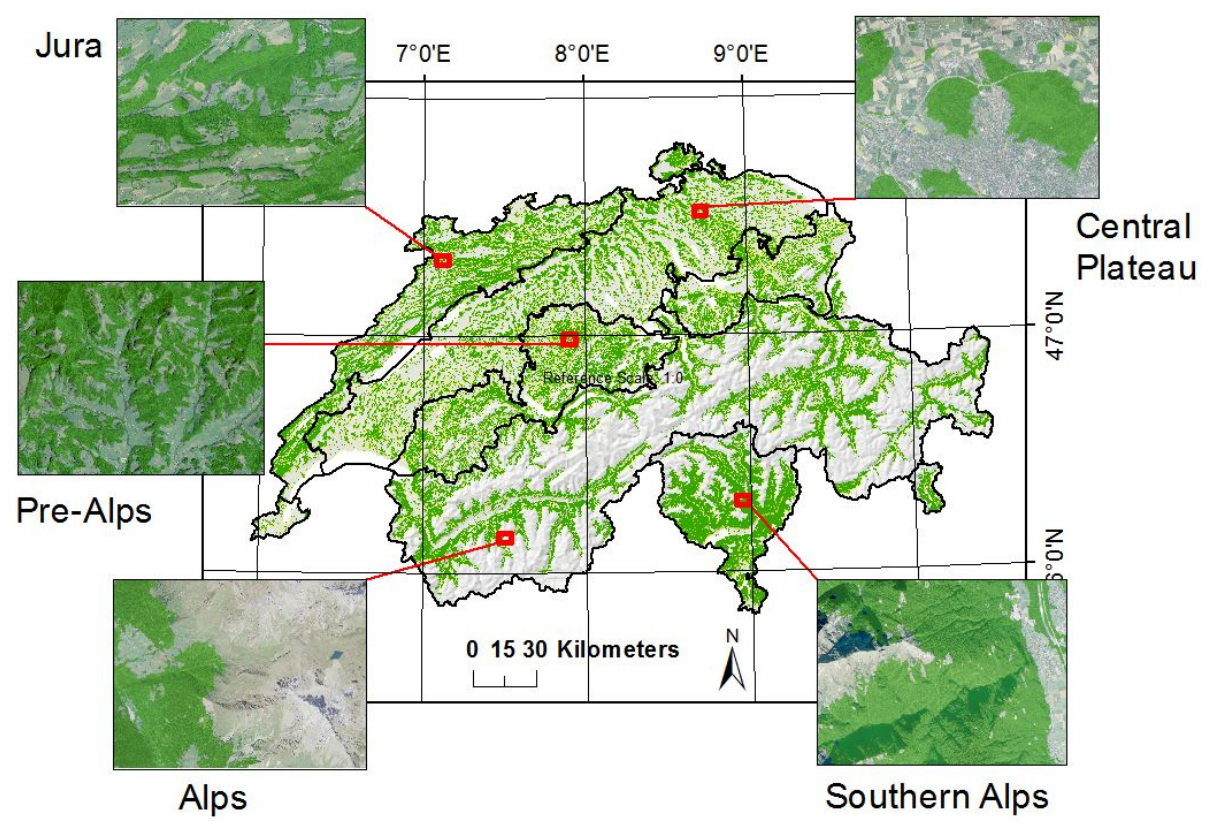

Figure 7. Forest cover map (green) covering all of Switzerland with the five production-region subsets and corresponding aerial images.

\subsection{Comparison with NFI Estimations}

Table 2 shows the comparison of the forest cover map with estimations and standard error (SE) from the NFI (sample plot extrapolations). The forest cover map revealed a larger forest area of $4.4 \%$. The absolute difference is 54,763 ha. In the Alps, the differences between the forest cover map and the NFI estimations is smallest (1.3\%) and rises for the other production regions (Prealps, Jura and Southern Alps) to $6.4 \%$ for the Central Plateau. 
Table 2. Comparison of the mapped forest cover area (in ha) for Switzerland and the five production regions with the corresponding estimations of the National Forest Inventory ( $S E \%$ in brackets).

\begin{tabular}{crrc}
\hline Production Region & Forest Cover Map (ha) & NFI (ha) (SE\%) & Difference \\
\hline Jura & 214,824 & $203,669(1)$ & $5.5 \%$ \\
Central Plateau & 248,285 & $233,454(1)$ & $6.4 \%$ \\
Prealps & 242,026 & $227,725(1)$ & $6.3 \%$ \\
Alps & 410,809 & $405,429(1)$ & $1.3 \%$ \\
Southern Alps & 177,827 & $168,731(2)$ & $5.4 \%$ \\
Switzerland & $1,293,771$ & $1,239,008(1)$ & $4.4 \%$ \\
\hline
\end{tabular}

\subsection{Comparison with NFI Sample Plot Data}

The validation based on 9984 NFI plots reveals an Overall Accuracy (OA) of 0.97 and a forest overestimation of $10.1 \%$ and an underestimation of $3.8 \%$ (see Table 3 ). More detailed analysis reveals that the lowest OA (0.91) is obtained for elevations between 1401 and $1800 \mathrm{~m}$ a.s.l and for the Southern Alps. The highest OA values are obtained for areas higher than $1800 \mathrm{~m}$ a.s.l. (0.99), and for the Central Plateau (0.98) and altitude classes lower than $600 \mathrm{~m}$ a.s.l (0.98), which belong mostly to the Central Plateau or to the lower valleys. In addition to the OA, the commonly used statistical measures error of commission (EC) and error of omission (EO) for the class "forest" were calculated (for details, see [46]). EC refers to the non-forest reference plots which belong to forest areas according to the forest cover map, whereas EO refers to forest reference plots which belong to non-forest areas according to the forest cover map. Differentiating between forest types (deciduous and coniferous) reveals that both have high OA with low EC. Obviously, both EO and EC rise with increasing altitude and are highest for areas higher than $1800 \mathrm{~m}$ a.s.l. This is quite similar for the five production regions with the exception of the Alps for which EC is lower.

Table 3. Accuracy assessment based on NFI sample plots with stratified validation incorporating all plots, NFI height levels, tree types, and NFI production regions.

\begin{tabular}{cccccc}
\hline Validation Based on & N Plots & OA & $\begin{array}{c}\text { Error of } \\
\text { Omission (\%) }\end{array}$ & $\begin{array}{c}\text { Error of } \\
\text { Commission (\%) }\end{array}$ \\
\hline All plots & & 9984 & 0.97 & 3.8 & 10.1 \\
\hline Height above sea level [m] & $600-1000$ & 2800 & 0.98 & 1.1 & 9.9 \\
& $1001-1400$ & 1114 & 0.94 & 2.3 & 10.1 \\
& $1401-1800$ & 878 & 0.91 & 10.2 & 10.5 \\
Deciduous & $>1800$ & 3087 & 0.99 & 19.7 & 17.6 \\
\hline Coniferous & & 797 & 0.98 & 1.5 & 0.8 \\
\hline \multirow{2}{*}{ Production region } & & 1372 & 0.96 & 4.1 & 0.3 \\
\hline & Jura & 1307 & 0.97 & 0.4 & 7.1 \\
& Central Plateau & 2471 & 0.98 & 1.7 & 13.5 \\
& Prealps & 1549 & 0.95 & 3.6 & 10.9 \\
& Alps & 4075 & 0.97 & 7.0 & 15.1 \\
\hline
\end{tabular}

Furthermore, the validation revealed that the distance to the forest border affects the OA of the forest cover map substantially (Figure 8). Obviously, OA increases strongly with increasing distances from reference plots to forest borders-independently of whether they are located inside or outside the forest areas. In particular, the increase in OA within the first $25 \mathrm{~m}$ from the forest border is very high (see Figure 8 vertical dashed line). When assessing all altitude classes together, OA of less than 0.6 are closer to the forest border and exceed OA of 0.8 for distances greater than $25 \mathrm{~m}$. The increase in OA from 0.8 to 0.9 is less steep. Considering plots with a distance of greater than or equal to $70 \mathrm{~m}$ from the forest border leads to an OA of greater than 0.9. Above this threshold, the continuous increase of 
OA is much less marked. When assessing the altitude classes independently differences between the classes are apparent. In general, the same pattern of OA increase can be observed for all classes, but the two highest classes show the lowest $\mathrm{OA}$ values.

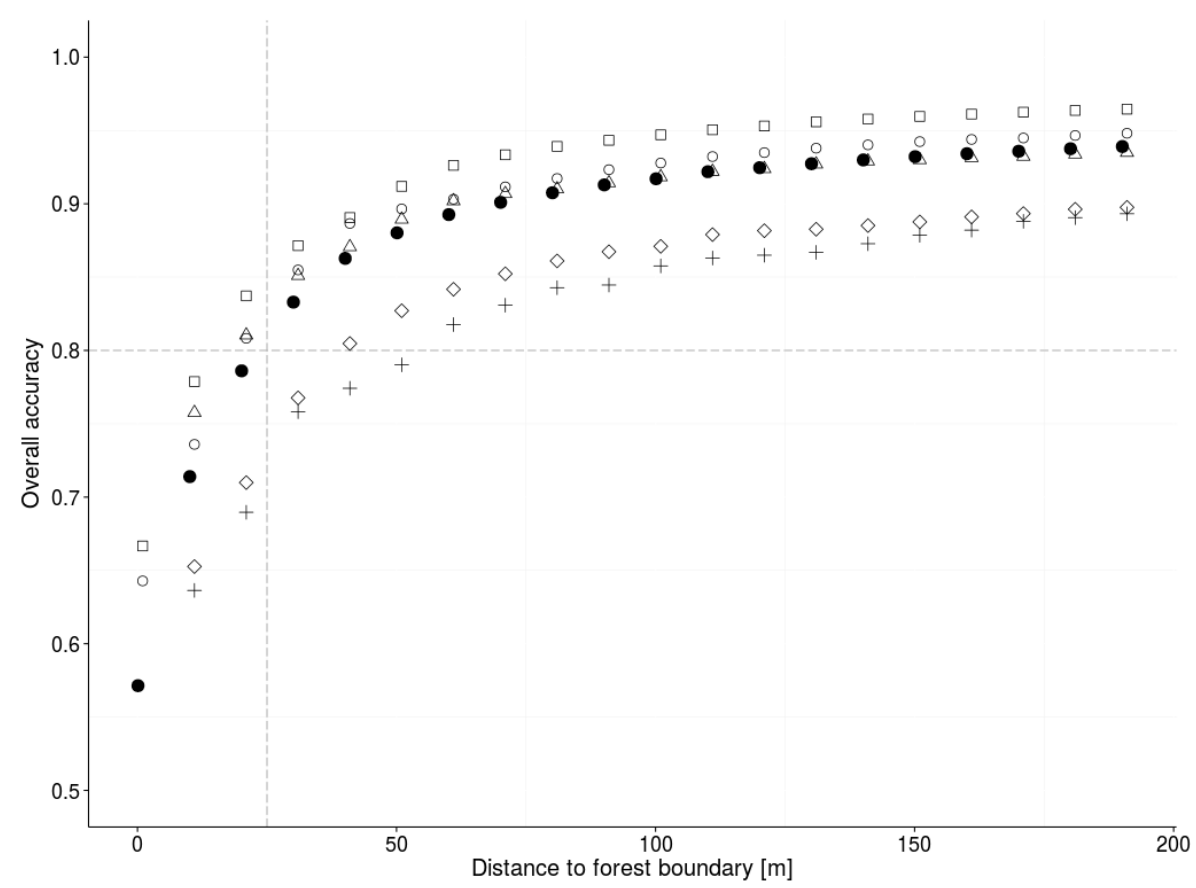

Figure 8. Overall accuracy dependent on the distance to the forest border and height above sea level (black dot $=$ all heights together; square $=$ lower than $600 \mathrm{~m}$ a.s.l.; circle $=600-1000 \mathrm{~m}$ a.s.1.; triangle $=1001-1400 \mathrm{~m}$ a.s.l.; diamond $=1401-1800 \mathrm{~m}$ a.s.l.; cross $=$ higher than $1800 \mathrm{~m}$ a.s.l.).

\section{Discussion and Conclusions}

\subsection{General Aspects of the Mapping Approach}

In the present study, a novel approach for wall-to-wall forest mapping of all of Switzerland $\left(41,285 \mathrm{~km}^{2}\right)$ based on image-based point clouds was developed revealing that $31 \%$ of the country is covered with forest. The approach is highly automated - with the exception of the land use criterion for which visual image interpretation and manual editing was needed. The most significant contribution of this study is that the forest cover map can be derived from image-based point clouds from routinely acquired aerial images (six-year cycle) and takes into consideration the forest definition of the Swiss NFI. Moreover, the results indicate that the method is promising and provides high overall accuracies of $97 \%$ for forest mapping in comparison to NFI reference data. These accuracies are in line with or higher than those reported in other studies $[18,19,29]$. However, first, it should be noted that a direct comparison is difficult less, because such studies mapped forest with different tree species compositions or involved a variety of forest structures and geographic locations, but more because of no NFI forest definition was used. Second, mapping areas in these studies were substantially smaller and different input data types, such as from ALS [25-27] or satellite data were used [20].

The comparison of the forest cover map area with the NFI forest area estimations revealed a larger forest area of $4.4 \%$ (Table 2). This can be explained by differences at the forest borders and is confirmed by a comparison at actual sample plot locations with an error of commission (EC) of $10.1 \%$ and an error of omission (EO) of $3.8 \%$ (Table 3).

Examining EC in detail, we find that they are low $(0.7 \%-10 \%)$, but increase with increasing altitude and mainly occur at the upper tree line (19.7\%), and are higher in coniferous plots. While the EO rate is at an acceptable level $(<2.3 \%)$ in areas below $1400 \mathrm{~m}$ a.s.l., it is rather high in the Alps $(7 \%)$ 
and Southern Alps (8.1\%). These underestimations are related to less distinct forest borders in these areas, less accurate VHM due to coarser image resolution, the simplified application of the minimum width, and the dominance of coniferous trees with narrow crowns (e.g., Pinus sylvestris)—which are difficult to detect. Furthermore, both comparisons revealed that EC are higher than EO indicating a general overestimation of forest area. While they remain stable at around $10 \%$, they also increase to a maximum of $17.6 \%$ at the upper tree line ( $>1800 \mathrm{~m}$ a.s.l.) and, therefore, in the corresponding production regions as well. It is obvious that these differences must be further minimized, whereas EO are more severe from the perspective that forest area has been irreversibly excluded from the mask (e.g., using a two phase sampling approach with the forest cover map as first phase data). In contrast, EC are more severe regarding the field work planning of a NFI. The validation also revealed that the forest cover map is more accurate in densely forested areas or entirely non-forested areas than at the forest border, and this accuracy increases with the distance from the border. For forest areas with distances of greater than $70 \mathrm{~m}$ from the forest borders, accuracy increases less and remains stable (Figure 8). The general constraints of the proposed method are discussed separately and more in detail below in Sections 5.2-4.

From a methodological point of view, the proposed method is appropriate for wall-to-wall mapping of entire countries. It is flexible regarding input datasets, such as VHMs based on ALS data. In fact, the VHM [37] is a reliable dataset and enables the derivation of the three geometric parameters of minimum height, minimum crown coverage and minimum width that are required for the NFI forest definition. Since these parameters are entirely based on the VHM they can be easily adapted to the thresholds required by other forest definitions, for example, as presented by [20,27].

The flexible adaptation to a different forest definition could be used for international reporting obligations of the Swiss NFI, e.g., for the Forest Resource Assessment (FRA) of FAO or the State of Europe's Forests report. The implementation of the three geometric land cover criteria (minimum height, crown coverage, and width of the NFI forest definition) was a less significant challenge for our approach than land use information. Although available for all European countries, the CLC2006 dataset was not an option in our approach due to its large minimum mapping units and the coarse spatial resolution of the input data $(100 \times 100 \mathrm{~m}$ and $250 \times 250 \mathrm{~m}$, respectively). Thus, the respective information was obtained from the Topographic Landscape Model (TLM). The forest class "closed forest" to compensate for temporarily unstocked forests areas, and the land classes "orchards" and "settlements" to eliminate forest on other land use (similar to other wooded land) were used. The main drawback was that additional manual work was necessary since the exact forest definition applied in the TLM is not entirely clear. Both TLM land layers were visually checked and polygons that were obviously wrong or too generalized were manually deleted.

\subsection{Constraints of the Forest Mapping Approach}

Sources of error in the forest cover map are manifold and are related to the imagery used, the straight-forward processing of the forest mapping-in particular regarding the complexity of forest borders, and inconsistencies in the forest definitions applied. The coarse image data resolution of $50 \mathrm{~cm}$ which is used to generate the VHM reduces the quality of the forest cover map for areas above $1500 \mathrm{~m}$ a.s.l. and results in generally lower accuracies for mountainous regions. This is in contrast to the Central Plateau and the Jura where the forest cover map is solely based on $25 \mathrm{~cm}$ resolution imagery. Moreover, although the quality of the ADS imagery is high and allows for robust image-matching, the resulting VHM is more error prone at forest borders. Due to oblique off-nadir objects-as a result of the central perspective of the images-hidden areas cannot be matched and thus are interpolated by the algorithm [37].

The general difference in forest area between the NFI estimations and the forest cover map is undoubtedly a weakness of the moving window approach. The most obvious reasons for EC and EO are separately described below. 
The applied shrinking function in order to eliminate narrow forest elements strongly depend on the minimum crown coverage criterion. It also depends on the crown coverage at this location inside the forest within the moving window. This may be too generalized when applying it to different forest types at different altitudes.

Moreover, according to Magdon and Kleinn [45], the simplified use of a constant buffer distance (15 m when using a CC of $20 \%$ and an interpretation area size of $51 \mathrm{~m}$, see Equation (1)) independent on the degree of forest fragmentation might be too generalized. Thus, the forest mapping approach might have introduced a bias which depends on the degree of fragmentation of the landscape, and in particular on the forest pattern and the resulting variability of the forest border (straight and irregular forest edges). It is assumed to be higher in highly fragmented landscapes than in compact ones although the differences become smaller the larger the interpretation area is [45].

\subsection{Errors of Commission}

Although the forest definition implemented in this approach is basically a good approximation it is still not $100 \%$ congruent with the true NFI forest definition. This is particularly essential at forest borders. In the Swiss NFI, the tree butt is used to define the forest border line, whereas it is the crown (canopy cover) in the mapping approach. Figure 9 illustrates that the greatest differences between the forest cover map and the reference plots occur at or near forest borders.

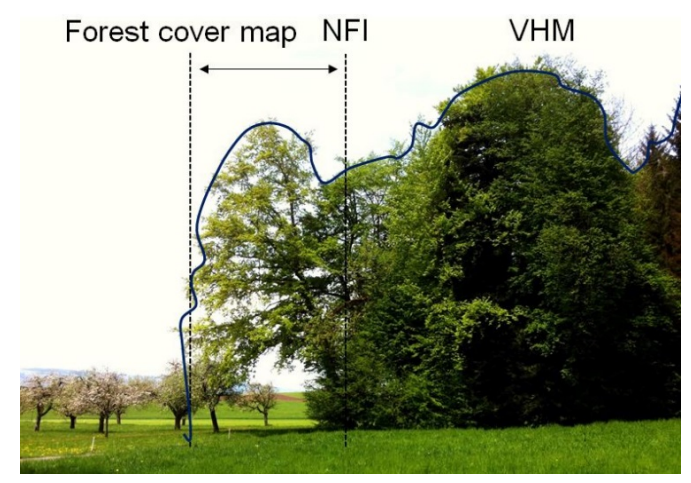

Figure 9. Overall accuracy at forest borders is affected by the different forest definitions as applied by the NFI and the forest cover map. The latter is based on the VHM in contrast to the tree butt by the NFI.

Moreover, a small number of EC are also the result of using NFI reference plots in areas that are located beside a street or river (wider than $6 \mathrm{~m}$ ) or crossed by them. According to the NFI, they are classified as non-forest but are located within dense forest in the forest cover map. Streets and rivers that cross forests are often hidden by the crown coverage in the VHM model due to the oblique crowns at the outer edges of the imagery and fuzzy forest borders from the image-matching algorithm. Consequently, they often belong to the forest cover map.

Although the classification of the VHM revealed a plausible picture of the stocked elements in the landscape, some errors occurred in high mountainous rocky areas. Here, the DTM from Swisstopo-which is based on ALS data and the DSM from the image-matching-had a slight horizontal mismatch. Along these cliffs, the calculated nDSM had a height of greater than $3 \mathrm{~m}$ and was thus classified as trees. If these artifacts cover larger areas and fulfill the NFI forest definition with a minimum crown coverage of higher than $20 \%$ and a width of greater than $25 \mathrm{~m}$, they were wrongly classified as forest.

A comparison with the crown coverage calculated from the aerial stereo-image interpretation of the NFI showed a slight overestimation of the coverage by the VHM (Median $=4.0$; RMSE $=16.8$; RMSE\% $\% 19.0)$. Again, due to the central perspective of the imagery, all objects that are away from the nadir line of the ADS image stripes are oblique. Although most nadir parts of the stripes were used for the image matching [37], small gaps between trees were hidden. 


\subsection{Errors of Omission}

Underestimation of forest area mainly occurs along forest borders, increases with altitude, and is consequently more distinctive for coniferous trees (4.1\%) than for deciduous trees (1.5\%) (Table 3). Again, image data with pixel size larger than of $50 \mathrm{~cm}$ - as it was used to generate the VHM in the mountains-causes more problems in the image-matching. Due to the larger pixel size, the smaller crowns of coniferous tree were less frequently detected in the VHM. Figure 10 illustrates the omission of mainly Pinus sylvestris in the Swiss National Park (Central Alps), which are characterized by very small tree crowns.
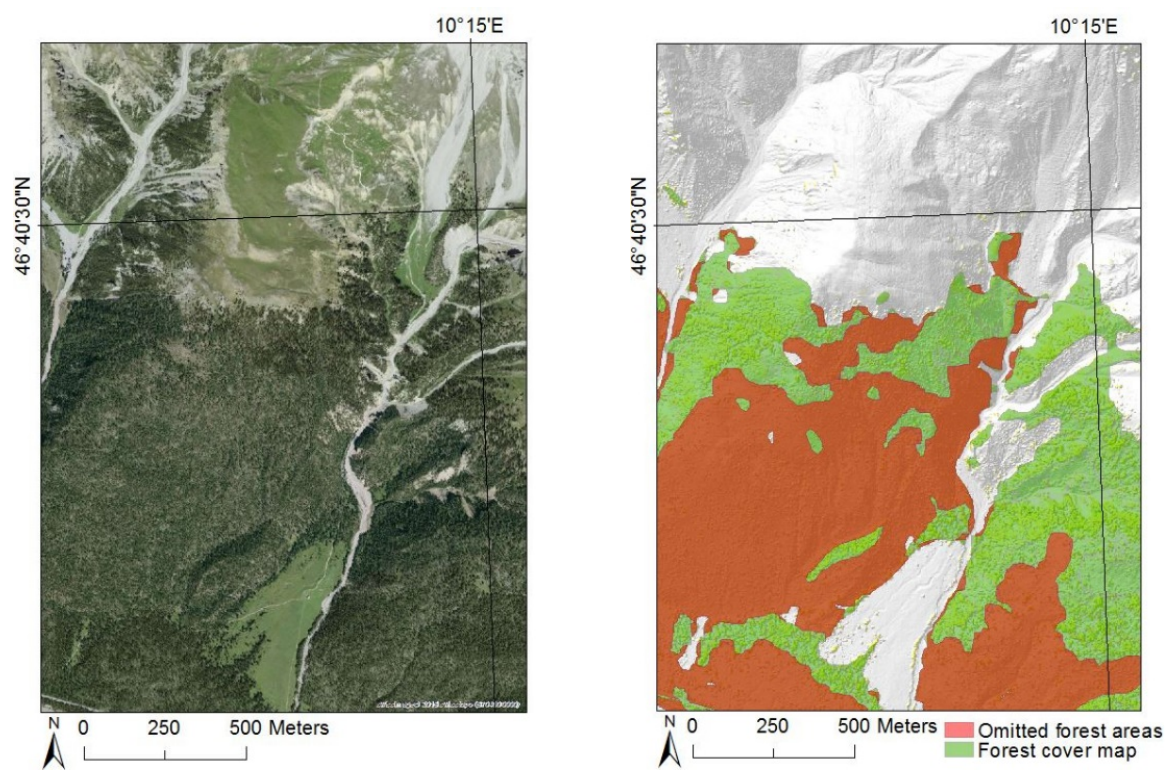

Figure 10. Underestimation of forest area in the Swiss National Park. Pinus sylvestris with very small crowns are clearly visible in the middle of the orthoimage (left), which were omitted in the shaded relief (light red areas) by the forest cover mapping approach (right).

Another problem is related to the NFI forest definition at the upper tree line. If the minimum crown coverage of greater than $20 \%$ is found (even if the height criteria is less than $3 \mathrm{~m}$ ), trees (e.g., Pinus mugo and Alnus viridis in Figure 11) are classified as shrub forest in the Swiss NFI. However, these short trees are excluded from the forest cover map since the minimum height criteria is not fulfilled.
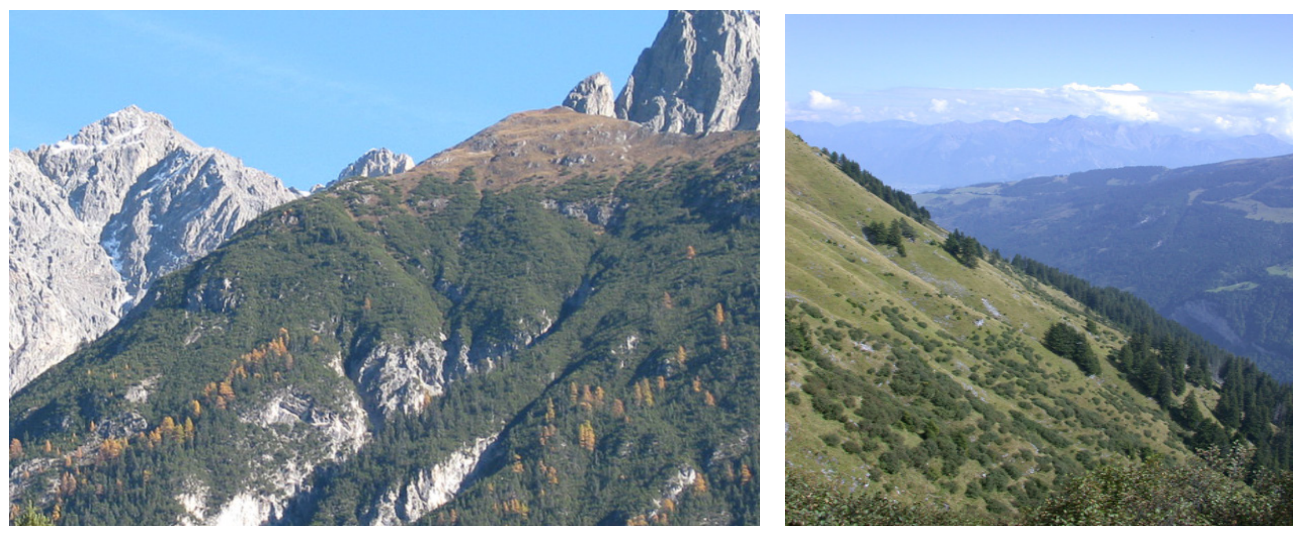

Figure 11. Examples of the upper tree line in steep terrain in the Swiss Alps with partly disperse Pinus mugo (left) and Alnus viridis (right). These areas are classified as shrub forest in the Swiss NFI but are partly excluded by the forest mapping approach. Photo (C) Urs-Beat Brändli, Swiss NFI. 


\subsection{Operational Use of the Forest Cover Map}

The main benefits of the forest cover map are manifold since it guarantees repeatable and objective results. Although the present forest cover map was developed for a relative small country, the recently increasing country-wide acquisition of 3D data (LiDAR or stereo-imagery) by many European countries will make its operational use more feasible. Restrictions are less related to acquisition of wall-to-wall 3D data and the extraction of the required forest definition criteria, but more to the availability of high-resolution land use maps.

For the Swiss NFI, the level of detailed and national wall-to-wall forest information makes it possible to densify the existing $1.4 \mathrm{~km}$ NFI sample plot grid for smaller areas of interest. It may also be used for an improved estimation of forest parameters such as timber volume for which forest area is an essential input parameter. The forest cover map may also enable further optimization of the planning and implementation of the terrestrial survey, which is very cost-effective. Although the $10 \%$ average commission error rate will result in too many non-forest plot visits, distinct non-forest plots can be excluded from the field planning process. Furthermore, in combination with forest road maps, it is a valuable information source to assess the accessibility of any forest area, and thus important for the reliable assessment of forest resource studies. Finally, a countrywide highly detailed forest cover map may serve as an important information source for many other regional or national uses, such as geological and geomorphological applications, avalanche or other hazard protection issues, as well as provide new perspectives for biodiversity or ecological connectivity studies.

\subsection{Outlook and Summary}

Further improvements to the proposed forest mapping approach are necessary to underscore its value as the basis for a countrywide dataset. The most significant opportunities for follow-up are:

- Differences between the NFI estimated forest area and the forest cover map can be further reduced by implementing the 1:1 minimum crown coverage and minimum width functions as used in the Swiss NFI.

- The shrinking functions applied to the forest cover map could be adapted, for instance, by using different thresholds for deciduous and coniferous dominated forest borders.

- The effect of different forest pattern on the landscape level, especially regarding forest edges for the proposed method should be further investigated as described in [45].

- Further research is also needed to improve the accuracy of the forest cover map at the upper tree line in the Alps. Image matching based on upcoming imagery with the same $25 \mathrm{~cm}$ spatial resolution that is standard for the Central Plateau in Switzerland will reduce the number of omitted narrow crowns of coniferous trees.

To summarize, the presented forest cover map approach is superior to existing products due to its national coverage, high level of detail, regular updating, and implementation of the land use criteria.

The focus was put on implementing the four criteria of minimum height, minimum crown coverage, minimum width, and land use in a comprehensible, geometrically clearly defined way, which also facilitates the production of a countrywide comparable forest cover map. It delivers repeatable and objective results, and will be of great practical relevance in the framework of a NFI, or for other applications that depend on an accurate and detailed countrywide forest cover map. Minimizing the error sources will underscore the advantages of wall-to-wall forest mapping approaches based on aerial stereo-imagery or, alternatively, on ALS data.

Acknowledgments: This study was funded by the Swiss National Forest Inventory (NFI), a cooperative effort between the Swiss Federal Institute for Forest, Snow and Landscape Research (WSL) and the Swiss Federal Office for the Environment (FOEN). We thank Curtis Gautschi for professional language editing. The authors are grateful to the two anonymous reviewers whose comments and suggestions significantly improved both clarity and precision of the paper. 
Author Contributions: Lars T. Waser and Christian Ginzler are responsible for the development of the study. Lars T. Waser is the main writer of the manuscript. Christian Ginzler and Zuyuan Wang developed the forest cover mapping methodology. Christoph Fischer contributed with R programming, statistical support, and the validation of results.

Conflicts of Interest: The authors declare no conflict of interest.

\section{References}

1. Food and Agriculture Organization (FAO). Global Forest Resources Assessment 2010: Main Report; FAO: Rome, Italy, 2010.

2. Hansen, M.C.; Potapov, P.V.; Moore, R.; Hancher, M.; Turubanova, S.A.; Tyukavina, A.; Thau, D.; Stehman, S.V.; Goetz, S.J.; Loveland, T.R.; et al. High-resolution global maps of 21st-century forest cover change. Science 2013, 342, 850-853. [CrossRef] [PubMed]

3. Lawrence, M.; McRoberts, R.E.; Tomppo, E.; Thomas, G.; Karl, G. Comparisons of National Forest Inventories. In National Forest Inventories-Pathways for Common Reporting; Tomppo, E., Gschwantner, T., Lawrence, M., McRoberts, R.E., Eds.; Springer Science and Business Media B.V.: Berlin, Germany, 2010; pp. 19-32.

4. Tomppo, E.; Gschwantner, T.; Lawrence, M.; McRoberts, R.E. National Forest Inventories-Pathways for Common Reporting; Springer Science and Business Media B.V.: Berlin, Germany, 2010; p. 612.

5. Koch, B.; Dees, M.; van Brusselen, J.; Eriksson, L.; Fransson, J.; Gallaun, H.; Leblon, B.; McRoberts, R.E.; Nilsson, M.; Schardt, M.; et al. Forestry applications. In Advances in Photogrammetry, Remote Sensing and Spatial Information-ISPRS 2008 Congress Book; Li, Z., Chen, J., Baltsavias, E., Eds.; Taylor \& Francis Group: London, UK, 2008; pp. 439-468.

6. Barrett, F.; McRoberts, R.E.; Tomppo, E.; Cienciala, E.; Waser, L.T. A questionnaire-based review of the operational use of remotely sensed data by national forest inventories. Remote Sens. Environ. 2016, in press.

7. Kleinn, C.; Ramírez, C.; Holmgren, P.; Lobo, S.; Chavez, G. A national forest resources assessment for Costa Rica based on low intensity sampling. For. Ecol. Manag. 2005, 210, 9-23. [CrossRef]

8. Maltamo, M.; Naesset, E.; Vauhkonen, J. Forestry applications of airborne laser scanning: Concepts and case studies. In Managing Forest Ecosystems 27; Springer Science and Business Media: Dodrecht, The Netherlands, 2014; p. 464.

9. McRoberts, R.E.; Liknes, G.C.; Domke, G.M. Using a remote sensing-based, percent tree cover map to enhance forest inventory estimation. For. Ecol. Manag. 2014, 331, 12-18. [CrossRef]

10. McRoberts, R.E.; Tomppo, E.O. Remote sensing support for national forest inventories. Remote Sens. Environ. 2007, 110, 412-419. [CrossRef]

11. Tomppo, E.; Haakana, M.; Katila, M.; Peräsaari, J. Multi-source national forest inventory-methods and applications. In Managing Forest Ecosystems 18; Springer Science and Business Media B.V.: Berlin, Germany, 2008.

12. Tomppo, E.; Halme, M. Using coarse scale forest variables as ancillary information and weighting of variables in k-NN estimation: A genetic algorithm approach. Remote Sens. Environ. 2004, 92, 1-20. [CrossRef]

13. Food and Agriculture Organization (FAO). Global Forest Land-Use Change 1990-2005; FAO: Rome, Italy, 2012.

14. The Global Forest Watch. Available online: http://www.globalforestwatch.org/map/3/15.00/27.00/ALL/ grayscale/loss,forestgain?begin=2001-01-01\&end=2015-01-01\&threshold=30 (accessed on 5 November 2015).

15. Bartholomé, E.; Belward, A.S. GLC2000: A new approach to global land cover mapping from Earth observation data. Int. J. Remote Sens. 2005, 26, 1959-1977. [CrossRef]

16. World's First High-Resolution Global Forest/Non-Forest Map. Available online: http://global.jaxa.jp/ article/special/geo/shimada_e.html (accessed on 5 November 2015).

17. European Joint Research Center JRC. Forest Cover Map-2006. Available online: http:/ / forest.jrc.ec.europa. eu/activities/forest-mapping/forest-cover-map-2006/ (accessed on 5 November 2015).

18. Waser, L.T.; Baltsavias, E.; Ecker, K.; Eisenbeiss, H.; Feldmeyer-Christe, E.; Ginzler, C.; Küchler, M.; Zhang, L. Assessing changes of forest area and shrub encroachment in a mire ecosystem using digital surface models and aerial images. Remote Sens. Environ. 2008, 112, 1956-1968. [CrossRef]

19. Wang, Z.; Ginzler, C.; Waser, L.T. A novel method to assess short-term forest cover changes based on digital surface models from image-based point clouds. Forestry 2015, 88, 429-440. [CrossRef]

20. Magdon, P.; Fischer, C.; Fuchs, H.; Kleinn, C. Translating criteria of international forest definitions into remote sensing image analysis. Remote Sens. Environ. 2014, 149, 252-262. [CrossRef] 
21. Eriksson, L.E.B.; Santoro, M.; Wiesmann, A.; Schmullius, C.C. Multitemporal JERS repeat-pass coherence for growing-stock volume estimation of siberian forest. IEEE Trans. Geosci. Remote Sens. 2003, 41, 1561-1570. [CrossRef]

22. Gebhardt, S.; Wehrmann, T.; Ruiz, M.; Maeda, P.; Bishop, J.; Schramm, M.; Kopeinig, R.; Cartus, O.; Kellndorfer, J.; Ressl, R.; et al. MAD-MEX: Automatic wall-to-wall land cover monitoring for the Mexican REDD-MRV program using all Landsat data. Remote Sens. 2014, 6, 3923-3943. [CrossRef]

23. Schepaschenko, D.; See, L.; Lesiv, M.; McCallum, I.; Fritz, S.; Salk, C.; Moltchanova, E.; Perger, C.; Shchepashchenko, M.; Shvidenko, A.; et al. Development of a global hybrid forest mask through the synergy of remote sensing, crowdsourcing and fao statistics. Remote Sens. Environ. 2015, 162, 208-220. [CrossRef]

24. Shimada, M.; Itoh, T.; Motooka, T.; Watanabe, M.; Shiraishi, T.; Thapa, R.; Lucas, R. New global forest/non-forest maps from ALOS PALSAR data (2007-2010). Remote Sens. Environ. 2014, 155, $13-31$. [CrossRef]

25. Mustonen, J.; Packalén, P.; Kangas, A. Automatic segmentation of forest stands using a canopy height model and aerial photography. Scand. J. For. Res. 2008, 23, 534-545. [CrossRef]

26. Straub, C.; Weinacker, H.; Koch, B. A fully automated procedure for delineation and classification of forest and non-forest vegetation based on full waveform laser scanner data. Int. Arch. Photogramm. Remote Sens. Spat. Inf. Sci. 2008, 37, 1013-1019.

27. Eysn, L.; Hollaus, M.; Schadauer, K.; Pfeifer, N. Forest delineation based on airborne lidar data. Remote Sens. 2012, 4, 762-783. [CrossRef]

28. White, J.C.; Wulder, M.A.; Vastaranta, M.; Coops, N.C.; Pitt, D.; Woods, M. The utility of image-based point clouds for forest inventory: A comparison with airborne laser scanning. Forests 2013, 4, 518-536. [CrossRef]

29. Waser, L.T.; Baltsavias, E.; Ecker, K.; Eisenbeiss, H.; Ginzler, C.; Küchler, M.; Thee, P.; Zhang, L. High-resolution digital surface models (DSMs) for modelling fractional shrub/tree cover in a mire environment. Int. J. Remote Sens. 2008, 29, 1261-1276. [CrossRef]

30. Wang, Z.; Boesch, R. Color-and texture-based image segmentation for improved forest delineation. IEEE Trans. Geosci. Remote Sens. 2007, 45, 3055-3062. [CrossRef]

31. Debella-Gilo, M.; Bjørkelo, K.; Breidenbach, J.; Rahlf, J. Object-based analysis of aerial photogrammetric point cloud and spectral data for land cover mapping. Int. Arch. Photogramm. Remote Sens. Spat. Inf. Sci. 2013, XL-1/W1, 63-67.

32. Reese, H.; Nordkvist, K.; Nyström, M.; Bohlin, J.; Olsson, H. Combining point clouds from image matching with SPOT 5 multispectral data for mountain vegetation classification. Int. J. Remote Sens. 2015, 36, 403-416. [CrossRef]

33. The topographic landscape model TML. Available online: http://www.swisstopo.admin.ch/internet/ swisstopo/en/home/topics/geodata/tlm.html (accessed on 6 November 2015).

34. Abegg, M.; Brändli, U.-B.; Cioldi, F.; Fischer, C.; Herold-Bonardi, A.; Huber, M.; Keller, M.; Meile, R.; Rösler, E.; Speich, S.; et al. Fourth National Forest Inventory-Result Tables and Maps on the Internet for the NFI 2009-2013 (NFI4b); Swiss Federal Institute for Forest, Snow and Landscape Research WSL: Birmensdorf, Switzerland, 2014.

35. Brändli, U.-B. Swiss National Forest Inventory. Results of the Third Assessment 2004-2006; Swiss Federal Institute for Forest, Snow and Landscape Research WSL: Birmensdorf, Switzerland, 2010; p. 312.

36. Waser, L.T. Airborne Remote Sensing Data for Semi-Automated Extraction of Tree Area and Classification of Tree Species. Ph.D. Thesis, ETH Zurich, Zurich, Switzerland, 2012.

37. Ginzler, C.; Hobi, M. Countrywide stereo-image matching for updating digital surface models in the framework of the Swiss national forest inventory. Remote Sens. 2015, 7, 4343-4370. [CrossRef]

38. Keller, M. Swiss National Forest Inventory. Manual for Terrestrial Survey; Swiss Federal Institute for Forest, Snow and Landscape Research WSL: Birmensdorf, Switzerland, 2013; p. 214.

39. R Core teAm. The R Manuals. Available online: http://cran.r-project.org/manuals.html (accessed on 16 September 2015).

40. Lund, H.G. Definitions of Forest, Deforestation, Afforestation, and Reforestation. Available online: https:/ / www.researchgate.net/publication/259821294_Definitions_of_Forest_Deforestation_Afforestation_ and_Reforestation (accessed on 11 December 2015). 
41. Lanz, A.; Brändli, U.-B.; Brassel, P.; Ginzler, C.; Kaufmann, E.; Thrürig, E. Switzerland. National Forest Inventories-Pathways for Common Reporting; Tomppo, E., Gschwantner, T., Lawrence, M., McRoberts, R.E., Eds.; Springer Science and Business Media B.V.: Berlin, Germany, 2010; pp. 555-565.

42. Brassel, P.; Lischke, H. Swiss National Forest Inventory: Methods and Models of the Second Assessment; Swiss Federal Institute for Forest, Snow and Landscape Research WSL: Birmensdorf, Switzerland, 2001.

43. Mathys, L.; Ginzler, C.; Zimmermann, N.E.; Brassel, P.; Wildi, O. Sensitivity assessment on continuous landscape variables to classify a discrete forest area. For. Ecol. Manag. 2006, 229, 111-119. [CrossRef]

44. Ginzler, C.; Bärtschi, H.; Bedolla, A.; Brassel, P.; Hägeli, M.; Hauser, M.; Kamphues, M.; Laranjeiro, L.; Mathys, L.; Uebersax, D.; et al. Aerial Image Interpretation LFI 3. Interpretationsanleitung zum Dritten Landesforstinventar; Swiss Federal Institute for Forest, Snow and Landscape Research WSL: Birmensdorf, Switzerland, 2005; p. 87.

45. Magdon, P.; Kleinn, C. Uncertainties of forest area estimates caused by the minimum crown cover criterion-A scale issue relevant to forest cover monitoring. Environ. Monit. Assess. 2013, 185, 5345-5360. [CrossRef] [PubMed]

46. Campbell, J.B.; Wynne, R.H. Introduction to Remote Sensing, 5th ed.; The Guilford Press: New York, NY, USA, 2011.

(C) 2015 by the authors; licensee MDPI, Basel, Switzerland. This article is an open access article distributed under the terms and conditions of the Creative Commons by Attribution (CC-BY) license (http://creativecommons.org/licenses/by/4.0/). 